\title{
Increased exhaled carbon monoxide concentration during living donor liver transplantation
}

\author{
TAKASHI MATSUSAKI ${ }^{1}$, HIROSHI MORIMATSU $^{1}$, TORU TAKAHASHI $^{1}$, MASAKI MATSUMI $^{1}$, KENJI SATO $^{1}$, \\ RYUJI KAKU ${ }^{1}$, TETSUFUMI SATO ${ }^{1}$, TAKAHITO YAGI ${ }^{2}$, NORIAKI TANAKA ${ }^{2}$ and KIYOSHI MORITA ${ }^{1}$ \\ Departments of ${ }^{1}$ Anesthesiology and Resuscitology, ${ }^{2}$ Surgery, \\ Okayama University Medical School, 2-5-1 Shikata-cho, Okayama 700-8558, Japan
}

Received August 31, 2007; Accepted October 19, 2007

\begin{abstract}
Exhaled carbon monoxide concentration (ExCO-C) has been reported to increase in oxidative tissue injuries such as systemic inflammation, and is thought to reflect increased heme breakdown in the affected organ. As a transplanted liver undergoes ischemia-reperfusion, we hypothesized that ExCO-C might also increase following liver transplantation and might serve as a measure of the severity of the graft tissue injury. We prospectively studied 67 living donor liver transplantation (LDLT) patients in a consecutive fashion. During anesthesia, ExCO-C was determined at 6 time points, ranging from anesthesia induction, to admission to the intensive care unit. We also measured two markers of endothelial cellular injury, i.e., serum soluble thrombomodulin (sTM) and intercellular adhesion molecule (ICAM)-1. At 5 min after reperfusion of the grafted liver, ExCO-C markedly increased from $5.69 \pm 2.34 \mathrm{ppm}$ at baseline, to $9.79 \pm 4.72 \mathrm{ppm}(\mathrm{p}<0.0001)$. There was an excellent correlation among an increase in CO concentration, arterial carboxyhemoglobin levels at the time of reperfusion $\left(\mathrm{r}^{2}=0.19, \mathrm{p}=0.0003\right)$, and postoperative total bilirubin levels (day 1, 2, and 3; $\mathrm{r}^{2}=0.102,0.109$ and 0.100 ; $\mathrm{p}=0.008,0.007$ and 0.010 , respectively). Serum sTM and ICAM-1 levels were also significantly increased after reperfusion (sTM: $3.3 \pm 0.8$ to $5.1 \pm 1.7 \mathrm{FU} / \mathrm{ml}, \mathrm{p}=0.0001$; ICAM-1: $271.9 \pm 86.3$ to $515.0 \pm 157.8 \mathrm{FU} / \mathrm{ml}, \mathrm{p}=0.0001)$. ExCO-C had a positive relationship with sTM $\left(\mathrm{r}^{2}=0.16\right.$, $\mathrm{p}=0.035)$ and ICAM-1 $\left(\mathrm{r}^{2}=0.12, \mathrm{p}=0.08\right)$. There was, however, no correlation of ExCO-C with serum AST/ALT levels or clinical outcomes. This study demonstrated that ExCO-C significantly increased after reperfusion during LDLT. The increased ExCO-C may likely reflect increased heme breakdown and endothelial cell injury in the grafted liver.
\end{abstract}

Correspondence to: Dr Toru Takahashi, Department of Anesthesiology and Resuscitology, Okayama University Medical School, 2-5-1 Shikata-cho, Okayama 700-8558, Japan

E-mail: takatoru@cc.okayama-u.ac.jp

Key words: bilirubin IX $\alpha$, carboxyhemoglobin, endothelial cell injury, heme oxygenase, ischemia-reperfusion

\section{Introduction}

Currently, liver transplantation is the only therapeutic modality available for the treatment of end-stage liver diseases such as hepatocellular carcinoma, liver cirrhosis, and fulminant hepatitis (1). However, the shortage of donor organs is a serious problem, and, in order to expand transplant candidacy, the number of living donor liver transplantation (LDLT) has recently been increased (2). LDLT requires cold preservation and warm revascularization of liver grafts prior to transplantation. Thus, a graft liver inevitably suffers from insults due to ischemia-reperfusion (I/R), which is a well-known oxidative stress $(3,4)$. There are, however, no available biomarkers that can be used to monitor I/R-induced tissue injury of the grafted liver during LDLT operation.

Endogenous carbon monoxide $(\mathrm{CO})$ is principally produced by heme catabolism in humans $(5,6)$. Heme oxygenase (HO)-1, the rate-limiting enzyme in heme catabolism, is induced by various types of oxidative stress which includes I/R (7-12). $\mathrm{HO}-1$ induction leads to increased heme breakdown, resulting in the production of iron, $\mathrm{CO}$, and biliverdin IX $\alpha$ which is subsequently reduced to bilirubin IX $\alpha$ by biliverdin reductase (13). CO synthesized through the $\mathrm{HO}$ reaction diffuses out of cells, enters the bloodstream to form carboxyhemoglobin $(\mathrm{CO}-\mathrm{Hb})$ and is transported to the lung where it is excreted in ambient air (14). We previously demonstrated that the exhaled carbon monoxide concentration (ExCO-C) is increased in critically ill patients with systemic inflammation, via increased heme breakdown (15), and it is suggested that ExCO-C may reflect the degree of oxidative tissue injuries in the affected organ. We thus hypothesized that ExCO-C might also increase during LDLT and reflect the severity of tissue injury of the graft due to I/R. In this study, we examined time course changes of ExCO-C during LDLT, and studied their relationship with the serum levels of two important molecular markers of endothelial injury, namely, soluble thrombomodulin (sTM) and intercellular adhesion molecule (ICAM)-1 (16-18).

\section{Materials and methods}

Patients. This study was conducted in conformity with the Declaration of Helsinki and was approved by the Institutional Review Board at Okayama University Medical School. After 
receiving the institutional approval and informed consent from study participants, we prospectively studied 67 (48 male, 19 female) LDLT patients between January 2004 and October 2005 at our institution in a consecutive manner.

Anesthetic procedure. All patients received general anesthesia with an endotracheal intubation. General anesthesia was induced by $2 \mathrm{mg} / \mathrm{kg}$ of propofol and $5 \mu \mathrm{g} / \mathrm{kg}$ of fentanyl with $0.1 \mathrm{mg} / \mathrm{kg}$ of vecuronium to facilitate endotracheal intubation. Anesthesia was maintained using continuous infusion of fentanyl and vecuronium at a rate of $2-4 \mu \mathrm{g} / \mathrm{kg} / \mathrm{h}$ and $2-4 \mathrm{mg} /$ $\mathrm{kg} / \mathrm{h}$, respectively, with 0.5 to $1.0 \%$ of isoflurane and oxygen/air mixture. For the first group of 35 patients (from January 2004 to December 2004) the fraction of inspired oxygen $\left(\mathrm{F}_{\mathrm{I}} \mathrm{O}_{2}\right)$ was increased from 0.6 to 1.0 at the time of graft reperfusion due to concerns about 'post reperfusion syndrome' (19). The level of $\mathrm{F}_{\mathrm{I}} \mathrm{O}_{2}=1.0$ was maintained for $1 \mathrm{~h}$ and then returned to 0.6 . Since the increase in inspired oxygen concentration may cause the elevation of $\mathrm{CO}$ concentration in exhaled air (20), for the second group of 32 patients (from January 2005 to October 2005), $\mathrm{F}_{\mathrm{I}} \mathrm{O}_{2}$ was maintained at 0.6 throughout the procedure. However, we did not encounter any hypoxemic episode during the procedure in the second group.

Transplantation procedure. The donor hepatectomy was performed using the standard technique for living donation (21). The recipient hepatectomy was also performed using the standard technique without veno-venous bypass (21). The grafted liver was then weighed and perfused through the portal vein by the University of Wisconsin (UW) solution with methylprednisolone $(20 \mathrm{mg} / \mathrm{kg})$. The volume of the solution was determined according to the weight of the graft $(1 \mathrm{ml} / \mathrm{g})$. The portal flush was performed by gravity. After perfusion, the graft was immersed in the UW solution and kept at $4^{\circ} \mathrm{C}$ for storage. Transplantation of the graft was performed using the piggyback technique. Before completion of the caval anastomosis, the graft was flushed through the portal vein with an average of $250 \mathrm{ml}$ of $5 \%$ albumin stored at $4{ }^{\circ} \mathrm{C}$. Hepatic artery reconstruction was performed by endto-end anastomosis under an operating microscope, followed by duct-to-duct biliary reconstruction (22).

Exhaled $\mathrm{CO}$ measurement. ExCO-C was measured using a newly developed CO analyzer (Carbolyzer ${ }^{\mathrm{TM}}$ mBA-2000, Taiyo Instruments, Inc., Osaka, Japan) as described previously (15). This instrument is equipped with a gas sensor based on the controlled potential electrolysis method (23) with sensitivity to $0.1 \mathrm{ppm}$ of $\mathrm{CO}$ and capability of continuous side-stream sampling. A sampling adaptor was attached to the respiratory circuit for exhaled air sampling. During anesthesia, ExCO-C was measured at the following 6 time points, i.e., i) after induction, (time 1); ii) pre-anhepatic phase (time 2); iii) anhepatic phase (time 3); iv) 5 min after reperfusion (time 4); v) $1 \mathrm{~h}$ after reperfusion (time 5); and vi) admission to the intensive care unit (ICU) (time 6). The measurement was carried out for $1 \mathrm{~min}$ at each time point and a mean ExCO-C was calculated using the special software package (Carbolyzer ${ }^{\mathrm{TM}}$ DataBox, Taiyo Instruments, Inc.). Respiratory status was corrected based on $\mathrm{PaCO}_{2}, \mathrm{PaO}_{2}$, and
Table I. Patient characteristics.

\begin{tabular}{lc}
\hline Age (in years) & $51.5 \pm 4.9$ \\
Gender ratio (F/M) & $19 / 48$ \\
Liver disease & \\
Viral disease & 39 \\
Non-viral disease & 22 \\
Fluminant hepatitis & 6 \\
Operation time (min) & $549.3 \pm 173.2$ \\
CIT (min) & $61.5 \pm 4.9$ \\
WIT (min) & $36.0 \pm 8.5$ \\
Bleeding (ml) & $3000 \pm 1414$ \\
GRW (\%) & $1.16 \pm 0.20$ \\
MELD score (point) & $18 \pm 4.2$ \\
\hline
\end{tabular}

Values are the means $\pm \mathrm{SD}$, or number of patients. CIT, cold ischemic time; WIT, warm ischemic time; GRW, graft volume/recipient body-weight ratio; and MELD, Mayo end-stage liver disease.

the respiratory rates that were also determined at the time of $\mathrm{CO}$ measurements.

Arterial CO-Hb measurement. Arterial CO-Hb concentration was measured as a percentage using a co-oximeter blood gas analyzer (ABL 735 System $^{\mathrm{TM}}$, Radiometer Medical A/S, Copenhagen, Denmark). This instrument was specifically adjusted to the absorption wavelength of CO-Hb (SAT 100), to permit the most accurate measurement of $\mathrm{CO}-\mathrm{Hb}$ concentration (24). The instrument was pre-calibrated by the manufacturer, based on heparinized blood samples that met with strict criteria for $\mathrm{pH}, \mathrm{pCO}_{2}, \mathrm{Hb}, \mathrm{FCO}-\mathrm{Hb}$, and FMet-Hb (25). Routine arterial blood gas analysis was performed at the same time of the measurements of ExCO-C.

Serum STM and ICAM-1 measurement. In 14 patients, serum was obtained from the arterial blood sampled at the same time as the $\mathrm{CO}$ measurement. Blood samples were drawn into $0.11 \mathrm{~mol} / 1$ sodium citrate $(9: 1)$, placed immediately on melting ice, and centrifuged within $30 \mathrm{~min}$. Serum was kept frozen at $-70^{\circ} \mathrm{C}$ until tested. Serum sTM and ICAM-1 concentrations were measured by microenzyme-linked immunosorbent assay (micro-ELISA), using the micro-ELISA plate coated with monoclonal antibodies (Human Thrombomodulin Immunoassay kit, Daiichi Fine Chemical Co. Ltd., Toyama, Japan and CellFree ${ }^{\text {TM }}$ Human sICAM-1 ELISA, Pierce Endogen, Rockford, IL), according to the manufacturer's protocol.

Postoperative biochemical determinations and clinical outcomes. Serum concentrations of total bilirubin (T-Bil), alanine aminotransferase (ALT) and aspartate aminotransferase (AST) were obtained from routine laboratory results at postoperative day $1,2,3$ and 7 . Data of clinical outcomes including acute cellular rejection, reintubation, bleeding required re-laparotomy, length of intensive care unit 
A

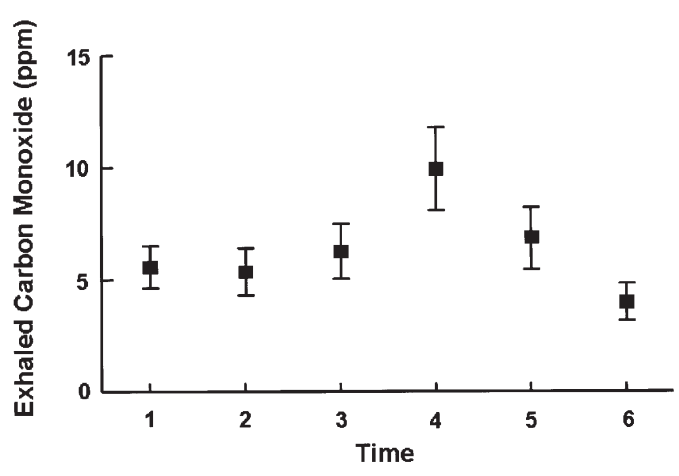

B

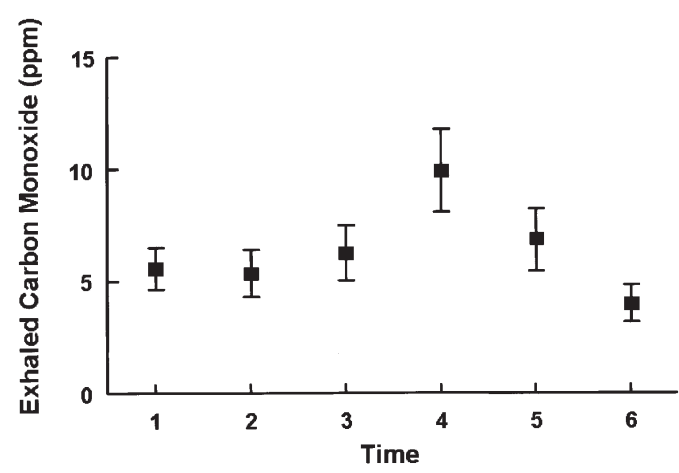

Figure 1. Changes in exhaled carbon monoxide concentrations during living donor liver transplantation with fraction of inspired oxygen $\left(\mathrm{F}_{\mathrm{I}} \mathrm{O}_{2}\right)=1.0$ (A) and $\mathrm{F}_{\mathrm{I}} \mathrm{O}_{2}=0.6(\mathrm{~B})$. Exhaled carbon monoxide concentrations markedly increased and reached a maximum at 5 min after reperfusion (time 4) and gradually decreased to baseline by the time of admission to the ICU (time 6) regardless of inspired oxygen concentration. (A) $\mathrm{F}_{\mathrm{I}} \mathrm{O}_{2}$ was increased from 0.6 to 1.0 at the time of graft reperfusion, which was maintained for $1 \mathrm{~h}$ and then returned to 0.6. (B) $\mathrm{F}_{\mathrm{I}} \mathrm{O}_{2}$ was maintained at 0.6 throughout the procedure. Data are expressed as the mean $\pm \mathrm{SD}$. The timing of measurement of exhaled carbon monoxide concentrations: time 1, after induction of anesthesia; time 2, pre-anhepatic phase; time 3, anhepatic phase; time 4, 5 min after reperfusion; time 5,1 h after reperfusion; and time 6 , admission to the intensive care unit.

stay, length of hospital stay, and hospital survival were also collected.

Statistical analysis. Data were expressed as the mean with standard deviation. Analyses were made using the Student's t-test, Pearson's correlation coefficients or analysis of variance as appropriate. $\mathrm{p}<0.05$ was considered statistically significant.

\section{Results}

From January 2004 to October 2005, 67 patients, 48 men and 19 women, mean age $51.5 \pm 4.9$ years, underwent LDLT. Underlying diseases of the transplant recipients included liver cirrhosis caused by viral hepatitis $(n=39)$, fulminant hepatitis $(n=6)$, and others $(n=22)$. Average Mayo end-stage liver disease score of these patients was $18 \pm 4.2$ (Table I). The donors included 36 men and 31 women; their mean age was $35 \pm 15.6$. Preoperative evaluation of the donors revealed

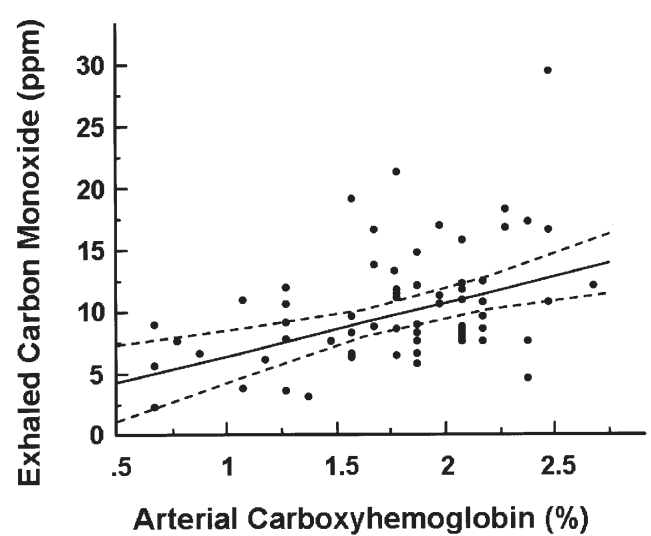

Figure 2. Relationship between exhaled carbon monoxide concentrations and arterial carboxyhemoglobin levels at 5 min after reperfusion (time 4). Exhaled carbon monoxide concentrations correlated positively with arterial carboxyhemoglobin levels $\left(\mathrm{r}^{2}=0.19, \mathrm{p}=0.0003\right)$. Liner regression line (solid line) with $95 \%$ confidence intervals (dotted lines) is presented.

that all of them had normal liver biochemical findings and bilirubin levels. The types of liver grafts were right lobe $(n=43)$, lateral lobe $(n=7)$, extended left lobe $(n=5)$ and left lobe $(n=12)$. The operation time of recipients was $549.3 \pm 173.2 \mathrm{~min}$; cold and warm ischemia times of the graft were $61.5 \pm 4.9 \mathrm{~min}$ and $36.0 \pm 8.5 \mathrm{~min}$, respectively. The graft volume/recipient body weight ratio was $1.16 \pm 0.20$ and blood loss during the recipient operation was $3000 \pm 1414 \mathrm{ml}$ (Table I).

We kept the respiratory condition constant during LDLT using anesthetic drugs with muscle relaxants. Throughout the entire anesthetic period, we controlled respiratory rate, $\mathrm{PaO}_{2}$, $\mathrm{PaCO}_{2}$ and $\mathrm{pH}$ to maintain the normal range by sequential measurements of arterial blood gas samples. Although there were still small fluctuations after normalization, it was essentially constant and stable, and time courses were comparable among all individuals, and between two groups of patients with different $\mathrm{F}_{\mathrm{I}} \mathrm{O}_{2}$ levels (Table II).

Although ExCO-C following LDLT (time 1) was significantly higher than those of healthy volunteers (14), CO concentration was essentially constant until the anhepatic phase (time 3) (Fig. 1). In the first 35 patients with $\mathrm{F}_{\mathrm{I}} \mathrm{O}_{2}=1.0$, ExCO-C significantly increased from $5.60 \pm 2.82 \mathrm{ppm}$ at the baseline (time 1) to $9.95 \pm 5.58 \mathrm{ppm} 5 \mathrm{~min}$ after reperfusion (time 4) $(\mathrm{p}<0.0001)($ Fig. 1A). The increased ExCO-C returned to the baseline (to $4.01 \pm 2.48 \mathrm{ppm}$ ) at the time of ICU admission (time 6) (Fig. 1A). Similarly, in the next 32 patients with $\mathrm{F}_{\mathrm{I}} \mathrm{O}_{2}=0.6$, ExCO-C increased from $5.77 \pm 1.61 \mathrm{ppm}$ at time 1 to $9.60 \pm 3.52 \mathrm{ppm}$ at time $4(\mathrm{p}<0.0001)$ (Fig. 1B). Thus there was no difference in ExCO-C at any point between the two groups of patients with different $\mathrm{F}_{\mathrm{I}} \mathrm{O}_{2}$ levels.

Changes in arterial $\mathrm{CO}-\mathrm{Hb}$ concentration during LDLT were similar to those of ExCO-C (Table II). At time 4, CO-Hb concentration was significantly correlated with ExCO-C $\left(r^{2}=0.19, p=0.0003\right)$ (Fig. 2). Both serum sTM and serum ICAM-1 concentration markedly increased after reperfusion from the pre-reperfusion level (sTM: $3.3 \pm 0.8 \mathrm{FU} / \mathrm{ml}$ to 5.1 $\pm 1.7 \mathrm{FU} / \mathrm{ml}, \mathrm{p}=0.0001$; ICAM-1: $271.9 \pm 86.3 \mathrm{FU} / \mathrm{ml}$ to $515 \pm 157.8 \mathrm{FU} / \mathrm{ml}, \mathrm{p}=0.0001$ ) (Fig. $3 \mathrm{~A}$ ). We also found that 
Table II. Respiratory conditions.

\begin{tabular}{|c|c|c|c|c|c|c|}
\hline & Time 1 & Time 2 & Time 3 & Time 4 & Time 5 & Time 6 \\
\hline \multicolumn{7}{|l|}{$\mathrm{F}_{\mathrm{I}} \mathrm{O}_{2}=1.0^{\mathrm{a}}$} \\
\hline $\mathrm{PaCO}_{2}(\mathrm{mmHg})$ & $35.3 \pm 3.7$ & $35.3 \pm 2.9$ & $34.3 \pm 2.9$ & $36.2 \pm 3.4$ & $38.7 \pm 3.4$ & $36.7 \pm 3.6^{c}$ \\
\hline $\mathrm{PaO}_{2}(\mathrm{mmHg})$ & $267 \pm 106$ & $225 \pm 57$ & $256 \pm 58$ & $455 \pm 70^{c}$ & $357 \pm 130^{c}$ & $210 \pm 61$ \\
\hline $\mathrm{RR}$ & $12.2 \pm 1.3$ & $12.1 \pm 0.9$ & $12.5 \pm 1.5$ & $12.7 \pm 1.5$ & $12.6 \pm 1.6$ & $14.0 \pm 2.3^{\mathrm{c}}$ \\
\hline $\mathrm{CO}-\mathrm{Hb}(\%)$ & $1.93 \pm 0.56^{\mathrm{c}}$ & $1.93 \pm 0.53$ & $1.95 \pm 0.46$ & $2.12 \pm 0.50$ & $1.65 \pm 0.42^{\mathrm{c}}$ & $1.63 \pm 0.40$ \\
\hline \multicolumn{7}{|l|}{$\mathrm{F}_{\mathrm{I}} \mathrm{O}_{2}=0.6^{\mathrm{b}}$} \\
\hline $\mathrm{PaCO}_{2}(\mathrm{mmHg})$ & $37.0 \pm 3.2$ & $36.1 \pm 2.6$ & $35.1 \pm 2.7$ & $36.5 \pm 2.9$ & $38.7 \pm 2.8$ & $39.8 \pm 3.2^{c}$ \\
\hline $\mathrm{PaO}_{2}(\mathrm{mmHg})$ & $244 \pm 73$ & $237 \pm 40$ & $247 \pm 37$ & $257 \pm 65^{\mathrm{c}}$ & $245 \pm 62^{c}$ & $169 \pm 61$ \\
\hline RR & $12.2 \pm 1.4$ & $12.0 \pm 1.6$ & $12.0 \pm 1.6$ & $12.1 \pm 1.4$ & $12.1 \pm 1.0$ & $12.6 \pm 1.4^{\mathrm{c}}$ \\
\hline $\mathrm{CO}-\mathrm{Hb}(\%)$ & $1.53 \pm 0.44^{\mathrm{c}}$ & $1.95 \pm 0.48$ & $1.91 \pm 0.41$ & $2.14 \pm 0.34$ & $1.94 \pm 0.45^{\mathrm{c}}$ & $1.8 \pm 0.29$ \\
\hline
\end{tabular}

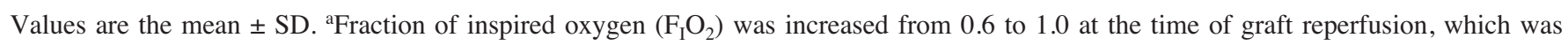
maintained for $1 \mathrm{~h}$ and then returned to $0.6 .{ }^{b} \mathrm{~F}_{\mathrm{I}} \mathrm{O}_{2}$ was maintained at 0.6 throughout the procedure. RR, respiratory rate. The timing of measurements: time 1, after induction of anesthesia; time 2, pre-anhepatic phase; time 3, anhepatic phase; time 4, 5 min after reperfusion; time $5,1 \mathrm{~h}$ after reperfusion; and time 6 , admission to the intensive care unit. ${ }^{c} \mathrm{P}<0.05$ in comparisons between the group of $\mathrm{F}_{\mathrm{I}} \mathrm{O}_{2}=1.0$ and the group of $\mathrm{F}_{\mathrm{I}} \mathrm{O}_{2}=0.6$.

A
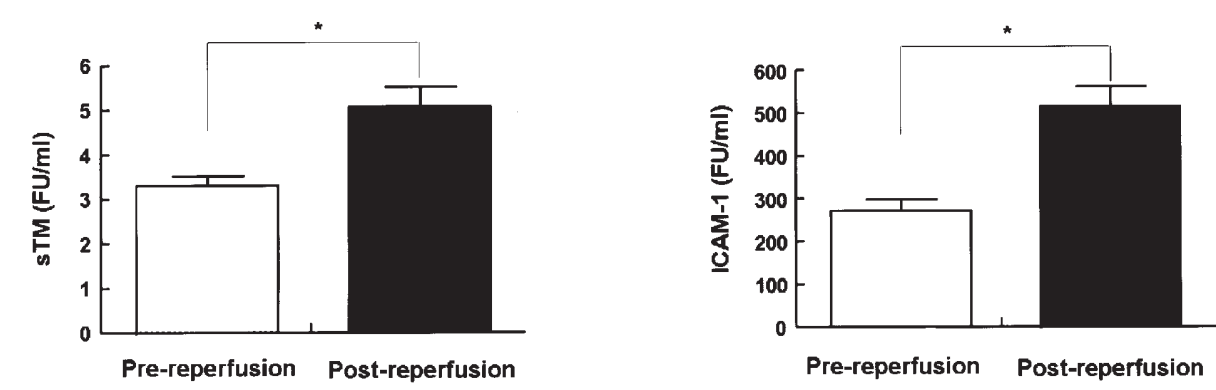

B
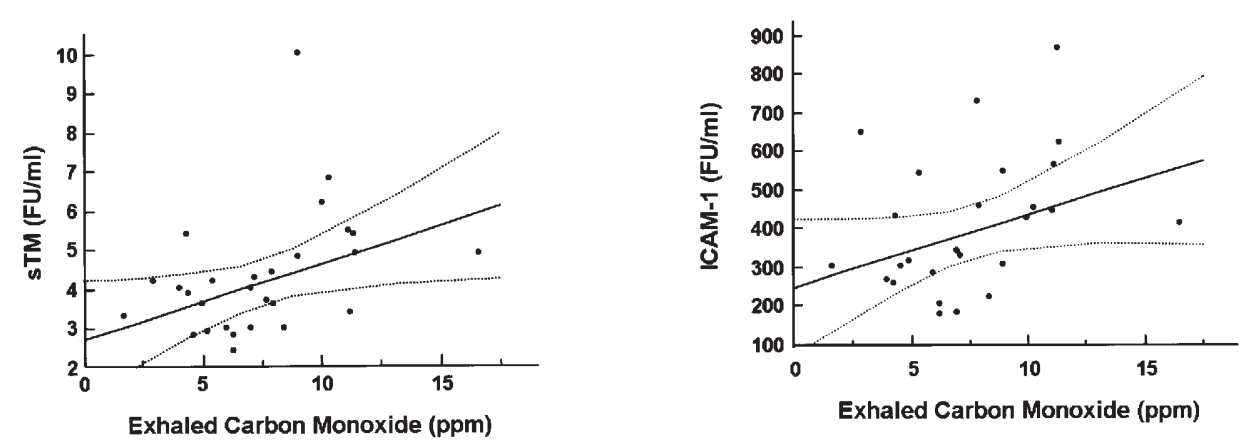

Figure 3. Serum concentrations of soluble thrombomodulin (sTM) and intercellular adhesion molecule-1 (ICAM)-1 at the time of pre- and post-reperfusion in 14 patients (A) and their relationship to exhaled carbon monoxide concentrations (B). (A) Both sTM (left) and ICAM-1 (right) levels significantly increased after reperfusion (sTM, ${ }^{*} \mathrm{p}=0.0001$; ICAM- $1,{ }^{*} \mathrm{p}=0.0001$, respectively). Data are expressed as the mean $\pm \mathrm{SD}$. (B) Exhaled carbon monoxide concentrations positively correlated with serum sTM $\left(\mathrm{r}^{2}=0.16, \mathrm{p}=0.035\right)$ (left) and ICAM-1 $\left(\mathrm{r}^{2}=0.12, \mathrm{p}=0.08\right)$ (right) levels, respectively. Liner regression line (solid line) with $95 \%$ confidence intervals (dotted lines) is presented. 
Table III. Relationship of peak exhaled carbon monoxide concentration to serum biochemical markers or clinical outcomes.

A, Biochemical markers

\begin{tabular}{|c|c|c|c|c|}
\hline & Day $^{\mathrm{a}} 1$ & Day $^{\mathrm{a}} 2$ & Day $^{\mathrm{a}} 3$ & Day $^{\mathrm{a}} 7$ \\
\hline T-Bil (mg/dl) & $6.49 \pm 3.20$ & $5.34 \pm 2.76$ & $4.81 \pm 2.93$ & $4.69 \pm 3.73$ \\
\hline $\mathrm{r}^{2}$ & 0.102 & 0.109 & 0.100 & 0.040 \\
\hline $\mathrm{p}$ value & 0.008 & 0.007 & 0.010 & 0.107 \\
\hline ALT (IU/dl) & $282 \pm 199$ & $273 \pm 407$ & $177 \pm 293$ & $92 \pm 115$ \\
\hline $\mathrm{r}^{2}$ & 0.015 & 0.042 & 0.056 & 0.001 \\
\hline $\mathrm{p}$ value & 0.320 & 0.090 & 0.050 & 0.815 \\
\hline AST (IU/dl) & $256 \pm 192$ & $308 \pm 298$ & $271 \pm 348$ & $202 \pm 250$ \\
\hline$r^{2}$ & 0.028 & 0.004 & 0.024 & 0.001 \\
\hline $\mathrm{p}$ value & 0.180 & 0.616 & 0.203 & 0.906 \\
\hline
\end{tabular}

B, Clinical outcomes

\begin{tabular}{lccc}
\hline & Yes & No & p value \\
\hline Acute cellular rejection & $9.67 \pm 0.90$ & $9.87 \pm 0.76$ & 0.86 \\
Reintubation & $10.32 \pm 1.50$ & $9.70 \pm 0.63$ & 0.70 \\
Bleeding & $10.92 \pm 1.58$ & $9.61 \pm 0.62$ & 0.44 \\
Survival & $9.83 \pm 0.62$ & $9.49 \pm 1.58$ & 0.84 \\
ICU stay & $\mathrm{r}^{2}=0.021$ & & 0.23 \\
Hospital stay & $\mathrm{r}^{2}=0.023$ & & 0.22 \\
\hline
\end{tabular}

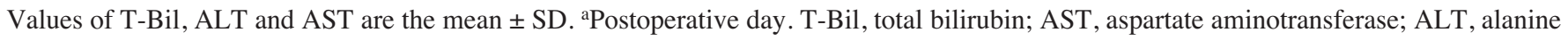
aminotransferase. Values of exhaled carbon monoxide concentration are the mean \pm SD.

ExCO-C had a significant positive correlation with serum sTM and ICAM-1 levels (sTM: $\mathrm{r}^{2}=0.16, \mathrm{p}=0.035$; ICAM- 1 : $r^{2}=0.12, p=0.08$, respectively) (Fig. 3B).

Serum T-Bil was highly elevated on postoperative day 1 , while it decreased gradually thereafter. We found there was a significant correlation between the peak of ExCO-C and serum T-Bil at postoperative day 1,2,3, but not at day 7 (Table IIIA). Serum AST and ALT levels were also markedly increased on postoperative day 1 and 2, followed by the gradual decrease thereafter. However, there was no significant correlation between ExCO-C and AST, or ALT levels, at all time points (Table IIIA). There was also no correlation between ExCO-C and postoperative complications and clinical outcomes (Table IIIB).

\section{Discussion}

There are no studies which have examined ExCO-C in LDLT, and this study is the first to describe significant changes in ExCO-C occurring immediately after LDLT. We found that ExCO-C markedly increased and reached a maximum at $5 \mathrm{~min}$ after reperfusion of the donor liver. Thereafter, it gradually decreased, and reached the baseline level by the time of admission to the ICU. Similar changes in ExCO-C were observed for two groups of patients with different $\mathrm{F}_{\mathrm{I}} \mathrm{O}_{2}$ conditions, i.e., $\mathrm{F}_{\mathrm{I}} \mathrm{O}_{2}=1.0$ and $\mathrm{F}_{\mathrm{I}} \mathrm{O}_{2}=0.6$. The increased ExCO-C was also correlated with the levels of serum STM and ICAM-1, the two markers of endothelial cell damages. These findings strongly suggest that increased ExCO-C may reflect the degree of endothelial injury of the grafted liver.

As shown in Fig. 1, ExCO-C markedly increased immediately after reperfusion of the grafted liver during LDLT, suggesting that hepatic I/R must have also resulted in a systemic increase in $\mathrm{CO}$ concentration prior to its increase in exhaled air. ExCO-C was also well correlated with arterial $\mathrm{CO}-\mathrm{Hb}$ concentration (Fig. 2). Previous studies reported that there was an increase in ExCO-C in inflammatory airway diseases, such as asthma, chronic obstructive pulmonary disease and cystic fibrosis (26-28). It has also been reported that ExCO-C was increased in systemic inflammatory diseases such as sepsis and critical illness (15,29-31). Our findings in this study have additionally shown that I/R during LDLT led to an increase in ExCO-C, and indicate that $\mathrm{I} / \mathrm{R}$ in LDLT is a significant oxidative stress on the grafted liver.

It has previously been suggested that changes in $\mathrm{F}_{\mathrm{I}} \mathrm{O}_{2}$ might influence ExCO-C (20,32). However, our findings showed that the peak concentration of exhaled $\mathrm{CO}$ after reperfusion was similar for two groups of patients with different $\mathrm{F}_{\mathrm{I}} \mathrm{O}_{2}$ levels, i.e., $\mathrm{F}_{\mathrm{I}} \mathrm{O}_{2}=1.0$ and $\mathrm{F}_{\mathrm{I}} \mathrm{O}_{2}=0.6$ (Fig. 1). Consistent with our findings, a recent study also reported that an increase in $\mathrm{F}_{\mathrm{I}} \mathrm{O}_{2}$ from 0.5 to 1.0 did not influence end-tidal $\mathrm{CO}$ concentration (32). These recent findings thus indicate that a $<2$-fold change in $\mathrm{F}_{\mathrm{I}} \mathrm{O}_{2}$ does not influence $\mathrm{CO}$ concentration in exhaled air. Other potential variables that might influence 
ExCO-C such as changes in respiratory status have been adjusted and rectified in our study, based on sequential measurements of $\mathrm{PaCO}_{2}, \mathrm{PaO}_{2}$, and respiratory rate throughout the entire period of observation (Table II).

It is known that cytochrome P450, a major hemeprotein in the liver, undergoes a rapid degradation by ischemia (33), which results in the release of free heme, followed by the production of $\mathrm{CO}$, iron, and biliverdin by the HO-mediated enzymatic process $(34,35)$. It is likely that a grafted liver may also undergo a similar change during LDLT, and may result in the production of $\mathrm{CO}$ from heme breakdown. Increased $\mathrm{CO}$ concentration from the graft would then be diffused into general circulation, ultimately resulting in exhaled air. A significant correlation between peak ExCO-C and serum T-Bil levels also strongly suggests that increased $\mathrm{CO}$ concentration in exhaled air may be due to heme breakdown in the grafted organ (Table IIIA).

While heme is required as the prosthetic group for hemoproteins that are essential for life, an excess amount of free heme is highly toxic to cells, as it catalyzes the production of oxygen radicals $(34,35)$. Free heme can also readily intercalate into the lipid bilayer, resulting in an oxidative damage of the cytoskeleton (34-36). Exposure of endothelial cells to hemin, an oxidized form of heme that is available as a chemical, is also known to stimulate the expression of adhesion molecules such as ICAM-1, VCAM-1, and E-selectin, indicating that it elicits significant tissue damages $(37,38)$. In order to counteract against such insults, the body is equipped with a mechanism to rapidly activate the $\mathrm{HO}-1$ gene to increase $\mathrm{HO}$ activity, which then eliminates free heme by converting it to $\mathrm{CO}$, iron and biliverdin IX $\alpha$ (7-10). Recent evidence suggests that all metabolites of heme can significantly contribute to the cellular defense mechanism, e.g., CO by suppressing apoptosis via activation of p38 MAPK, iron by inducing an acute phase reactant ferritin, and biliverdin by its anti-oxidant property (7-10). Our findings also showed that serum levels of sTM and ICAM-1 after reperfusion were increased, suggesting that there was in fact significant endothelial cell damages in the grafted liver (Fig. 3), and that HO-1 induction took place as judged by an increase in ExCO-C, as cellular defense against the I/R-mediated insult (Fig. 1).

A significant relationship between peak ExCO-C and serum T-Bil levels was observed on day 1, 2, and 3 after LDLT, but not on day 7 (Table IIIA). This finding suggests that changes in ExCO-C may be very rapid but reversible, and related only to changes reflecting heme breakdown such as serum T-Bil and arterial $\mathrm{CO}-\mathrm{Hb}$ concentration (Table IIIA, Fig. 2). There was also no significant correlation of elevated CO concentration with serum AST/ALT, or clinical outcomes (Table III). These results thus suggest that ExCO-C might be a very sensitive and reversible marker for early changes, but may not be related to prolonged changes such as serum ALT and AST levels.

In conclusion, our finding in this study demonstrated that ExCO-C significantly increased immediately after reperfusion during LDLT. The increased ExCO-C may likely reflect heme breakdown in the grafted liver, as it was also associated with increases in the serum T-Bil concentration and in arterial $\mathrm{CO}-\mathrm{Hb}$ concentration. While ExCO-C might be an attractive marker for certain changes reflecting graft injury that can be monitored in a non-invasive manner, its value as a useful clinical marker is yet to be demonstrated with respect to other aspects associated with LDLT.

\section{Acknowledgements}

This study was supported in part by grants from Grant-in-Aid for Scientific Research from the Ministry of Education, Culture, Sports, Science, and Technology of Japan. We are grateful to Dr Shigeru Sassa for reviewing our manuscript. We also thank Dr Reiko Akagi (Okayama Prefectural University, Soja, Japan) for her encouragement toward this study.

\section{References}

1. Said A, Einstein M and Lucey MR: Liver transplantation: an update 2007. Curr Opin Gastroenterol 23: 292-298, 2007.

2. Brown RS Jr, Russo MW, Lai M, Shiffman ML, Richardson MC, Everhart JE and Hoofnagle JH: A survey of liver transplantation from living adult donors in the United States. N Engl J Med 348: 818-825, 2003.

3. Farmer DG, Amersia F, Kupiec-Weglinski JW and Busuttil RW: Current status of ischemia and reperfusion injury in the liver. Transplant Rev 14: 106-126, 2000.

4. Kupiec-Weglinski JW and Busuttil RW: Ischemia and reperfusion injury in liver transplantation. Transplant Proc 37: 1653-1656, 2005.

5. Marilena G: New physiological importance of two classic residual products: carbon monoxide and bilirubin. Biochem Mol Med 61: 136-142, 1997.

6. Sassa S: Inhibition of carbon monoxide production by tinprotoporphyrin. J Pediatr Gastroenterol Nutr 6: 167-171, 1987.

7. Takahashi T, Morita K, Akagi R and Sassa S: Heme oxygenase-1: a novel therapeutic target in oxidative tissue injuries. Curr Med Chem 11: 1545-1561, 2004.

8. Takahashi T, Morita K, Akagi R and Sassa S: Defense against oxidative tissue injury: the essential role played by heme oxygenase-1. Curr Enzyme Inhib 2: 105-124, 2006.

9. Takahashi T, Shimizu H, Akagi R, Morita K and Sassa S: Heme oxygenase-1: a new drug target in oxidative tissue injuries in critically ill conditions. Drug Dev Res 67: 130-153, 2006.

10. Takahashi T, Shimizu H, Morimatsu H, Inoue K, Akagi R, Morita K and Sassa S: Heme oxygenase-1: a fundamental guardian against oxidative tissue injuries in acute inflammation. Mini Rev Med Chem 7: 745-753, 2007.

11. Kawakami T, Takahashi T, Shimizu H, Nakahira K, Takeuchi M, Katayama H, Yokoyama M, Morita K, Akagi R and Sassa S: Highly liver-specific heme oxygenase-1 induction by interleukin-11 prevents carbon tetrachloride-induced hepatotoxicity. Int J Mol Med 18: 537-546, 2006.

12. Tomita M, Okuyama T, Katsuyama H, Hidaka K, Otsuki T and Ishikawa T: Gene expression in rat lungs during early response to paraquat-induced oxidative stress. Int J Mol Med 17: 37-44, 2006.

13. Shibahara S: Regulation of heme oxygenase gene expression. Semin Hematol 25: 370-376, 1988.

14. Coburn RF, Forster RE and Kane PB: Considerations of the physiological variables that determine the blood carboxyhemoglobin concentration in man. J Clin Invest 44: 1899-1910, 1965 .

15. Morimatsu H, Takahashi T, Maeshima K, Inoue K, Kawakami T, Shimizu H, Takeuchi M, Yokoyama M, Katayama $\mathrm{H}$ and Morita K: Increased heme catabolism in critically ill patients: correlation among exhaled carbon monoxide, arterial carboxyhemoglobin, and serum bilirubin IXalpha concentrations. Am J Physiol Lung Cell Mol Physiol 290: L114-L119, 2006.

16. Boffa MC and Karmochkine M: Thrombomodulin: an overview and potential implications in vascular disorders. Lupus 7 (suppl 2): 120-125, 1998.

17. Gearing AJ and Newman W: Circulating adhesion molecules in disease. Immunol Today 14: 506-512, 1993.

18. Siemianowicz K, Francuz T, Gminski J, Telega A and Syzdol M: Endothelium dysfunction markers in patients with diabetic retinopathy. Int J Mol Med 15: 459-462, 2005. 
19. Aggarwal S, Kang Y, Freeman J, DeWolf AM and Begliomini B: Is there a post-reperfusion syndrome? Transplant Proc 21: 3497-3499, 1989.

20. Zegdi R, Caid R, Van De Louw A, Perrin D, Burdin M, Boiteau R and Tenaillon A: Exhaled carbon monoxide in mechanically ventilated critically ill patients: influence of inspired oxygen fraction. Intensive Care Med 26: 1228-1231, 2000.

21. Tanaka K, Kobayashi Y and Kiuchi T: Current status of living donor liver transplantation in adults. Curr Opin Organ Transplant 5: 74-79, 2000.

22. Matsuda H, Yagi T, Sadamori H, Matsukawa H, Shinoura S, Murata H, Umeda Y and Tanaka N: Complications of arterial reconstruction in living donor liver transplantation: a singlecenter experience. Surg Today 36: 245-251, 2006.

23. Osteryoung J: Electrochemical methods of analysis. Methods Enzymol 158: 243-267, 1988.

24. Westphal M, Eletr D, Bone HG, Ertmer C, Weber TP, Aken HV and Booke M: Arteriovenous carboxyhemoglobin difference in critical illness: fiction or fact? Biochem Biophys Res Commun 299: 479-482, 2002.

25. Weber TP, Grosse Hartlage MA, Meyer J, Van Aken H, Uhlig S and Rolf N: Arteriovenous carboxyhemoglobin gradient is a technical artifact that is eliminated by special calibration (SAT 100). Biochem Biophys Res Commun 278: 447-448, 2000.

26. Horvath I, Donnelly LE, Kiss A, Paredi P, Kharitonov SA and Barnes PJ: Raised levels of exhaled carbon monoxide are associated with an increased expression of heme oxygenase- 1 in airway macrophages in asthma: a new marker of oxidative stress. Thorax 53: 668-672, 1998.

27. Montuschi P, Kharitonov SA and Barnes PJ: Exhaled carbon monoxide and nitric oxide in COPD. Chest 120: 496-501, 2001.

28. Paredi P, Shah PL, Montuschi P, Sullivan P, Hodson ME, Kharitonov SA and Barnes PJ: Increased carbon monoxide in exhaled air of patients with cystic fibrosis. Thorax 54: 917-920, 1999.
29. Scharte M, Bone HG, Van Aken H and Meyer J: Increased carbon monoxide in exhaled air of critically ill patients. Biochem Biophys Res Commun 267: 423-426, 2000.

30. Scharte M, von Ostrowski TA, Daudel F, Freise H, Van Aken H and Bone HG: Endogenous carbon monoxide production correlates weakly with severity of acute illness. Eur J Anaesthesiol 23: 117-122, 2006.

31. Zegdi R, Perrin D, Burdin M, Boiteau R and Tenaillon A: Increased endogenous carbon monoxide production in severe sepsis. Intensive Care Med 28: 793-796, 2002.

32. Schober P, Kalmanowicz M and Loer SA: Effects of inspiratory oxygen concentration on endtidal carbon monoxide concentration. J Clin Monit Comput 20: 89-94, 2006.

33. Ferrero ME, Orsi R and Bernelli-Zazzera A: Effects of ischemia on drug-metabolizing microsomal enzymes in rat liver. Exp Mol Pathol 28: 256-266, 1978.

34. Sassa S: Why heme needs to be degraded to iron, biliverdin IXalpha, and carbon monoxide? Antioxid Redox Signal 6: 819-824, 2004.

35. Sassa S: Biological implications of heme metabolism. J Clin Biochem Nutr 38: 138-155, 2006.

36. Jeney V, Balla J, Yachie A, Varga Z, Vercellotti GM, Eaton JW and Balla G: Pro-oxidant and cytotoxic effects of circulating heme. Blood 100: 879-887, 2002.

37. Wagener FA, da Silva JL, Farley T, de Witte T, Kappas A and Abraham NG: Differential effects of heme oxygenase isoforms on heme mediation of endothelial intracellular adhesion molecule 1 expression. J Pharmacol Exp Ther 291: 416-423, 1999.

38. Wagener FA, Eggert A, Boerman OC, Oyen WJ, Verhofstad A, Abraham NG, Adema G, van Kooyk Y, de Witte T and Figdor CG: Heme is a potent inducer of inflammation in mice and is counteracted by heme oxygenase. Blood 98: 1802-1811, 2001. 